\title{
Level of resilience in the elderly according to the Connor-Davidson scale: a systematic review
}

Maryanne Rodrigues Lemes' (ID) Leonardo Cesar Caldato Brabo Alves' (ID Mirian Ueda Yamaguchil,2 (ID

\section{Abstract}

Objective: To identify studies on resilience in the elderly measured by the Connor-Davidson scale. Method: A systematic review of literature on the level of resilience of the elderly was carried out, based on articles indexed in the Lilacs, IBECS, MedLine and PubMed databases, according to the Prisma method. Results: 27 studies were identified which included the elderly in their samples and determined the level of resilience through the Connor-Davidson scale. The USA (6), China (6) and Australia (5) had the greatest number of articles. A study carried out with elderly people in Australia had the highest level of resilience, which was attributed to public policies that favor the resilience development capacity of the population. The lowest level of resilience was observed in Japan in a study with survivors of major natural disasters, highlighting resilience as a significant protective factor for elderly persons who experience such events during their lives. Conclusion: The studies recognize resilience as an important protective factor for coping with external adversities and natural events, whether arising from the effects of the aging process on health, or through disease.

\footnotetext{
Centro Universitário de Maringá (UniCesumar), Programa de Graduação em Medicina. Maringá, Paraná, Brasil.

2 Centro Universitário de Maringá (UniCesumar), Instituto Cesumar de Ciência, Tecnologia e Inovação (ICETI), Programa de Pós-graduação em Promoção da Saúde. Maringá, Paraná, Brasil.
}

Funding: Instituto Cesumar de Ciência, Tecnologia e Inovação (ICETI), Bolsa de Pesquisa Produtividade. Process 85961/2018

\section{Keywords: Resilience}

Psychological. Health of the Elderly. Diabetes Mellitus.

Health Personnel. Neoplasms. 


\section{INTRODUCTION}

The world is at the center of a unique and irreversible demographic transition that will result in older populations everywhere ${ }^{1}$.

The 2015 World Report on Aging and Health ${ }^{2}$ provides an up to date vision of the changes in perceptions of health and aging. Skill losses in the elderly are vaguely related to the chronological age of the individual; differences between one elderly person and another, in terms of their abilities and needs, originate from events that occur throughout the life course of each individual, and are often modifiable, underlining the importance of the life cycle to understanding the aging process. It points out that although most older adults have multiple health problems, over time advanced age does not necessarily lead to poor quality of life.

Given this, resilience represents a dynamic development process, which encompasses positive adaptation in a context of significant threat, severe adversity or trauma ${ }^{3}$. Originating in the physical sciences, the use of the concept of resilience in the field of health sciences dates from the 1970s, with studies on people who despite having been subjected to acute or prolonged trauma - factors considered a risk for the development of mental illnesses - did not become ill as expected. One of the first studies to cite resilience was one by Gayton et al. ${ }^{4}$ on the emotional impact on people from families with children with cystic fibrosis.

The concept of resilience has distinct characteristics based on the country of origin. In the USA, the term resilience originated as a practical, individual-oriented perspective, while in Europe it was conceived from a more focused perspective on aspects of psychoanalysis and ethics. In Latin America, the concept of resilience emerged later and denotes a community-centered theoretical basis, with a greater focus on the themes of vulnerable populations, victims of violence and those on the fringes of society ${ }^{5}$.

In Brazil, the first studies on resilience emerged in 1996 and 1998 in research on children exposed to situations of risk, factors of psychosocial protection and vulnerability, social and emotional support networks for children at risk and in the occupational area associated with resilience in the profile of executives. In short, research on resilience as a central theme or associated with other Brazilian aspects has been developing since the $2000 \mathrm{~s}^{6}$.

In the context of health promotion, active aging and resilience converge in the same direction. Increasing life expectancy demands strategies for active aging and requires, in addition to the ability to adapt and withstand challenges throughout the course of life, the development of a truly resilient and adapted society ${ }^{7,8}$.

The concept of resilience is occupying an increasingly greater space in the gerontological discussion, but it is still a little studied subject in Brazil ${ }^{1}$. Studying the importance of resilience throughout life and its significance may be important in the coming years for the development of agingrelated policies and also in gerontological research that explores its multiple dimensions and wide range of determinants.

The aim of the present study was to perform a systematic review of levels of resilience in the elderly, as measured by the Connor-Davidson scale.

\section{METHOD}

A systematic review of Brazilian and international scientific literature on the resilience levels of the elderly was performed. The object of analysis was scientific production published in journals indexed in the Latin American and Caribbean Health Sciences Literature databases (Lilacs), the Spanish Bibliographic Index of Health Sciences (IBECS), the National Library of Medicine (MedLine) available via the Virtual Health Library (VHL) through the website www.bvsalud.org, and also from the United States National Library of Medicine (PubMed), accessed by the site http://www.ncbi.nlm.nih.gov/ pubmed. This survey was conducted in accordance with the methodological recommendations of the Preferred Reporting Items for Systematic Reviews and Meta-analyses (PRISMA).

The document search was conducted from May to July 2018 and the following words were used as keywords: "resilience scale" and "Connor-Davidson 
resilience scale". The following filters were applied to the Lilacs, IBECS and Medline databases: human, elderly, complete text and year of publication from 2013 to 2018, while the equivalent English filters were applied in the PubMed database: +65 years, clinical trial, 5 years publication dates and bumans. Review articles and instrument validation articles were excluded.

To select the studies, two researchers worked in parallel using the following inclusion criteria: publications between 2013 and 2018; use of the 25-question Connor-Davidson instrument (CD-RISC $25)$ validated in the country of origin; presentation of average resilience level score (score); inclusion of people over 65; publication in Portuguese, English or Spanish.

The CD-RISC $25^{10}$ scale assesses resilience through 25 items related to interpersonal relationships; religiosity; adversities; confidence and esteem for challenges; seeing the humorous side of things and the reasons they happen; dealing with stress; recovery time after illness; injuries and difficulties; adaptation to unpleasant and painful feelings; ability to do one's best in any situation; can achieve one's goals; do not give up; have someone to ask for help; ability to handle pressure; solve problems; are not discouraged after failure; recognize oneself as strong; make difficult decisions and enjoy success. For each question on the questionnaire, there is a Likert scale answer option, ranging from zero (not at all true) to four (totally true) ${ }^{10}$.

\section{RESULTS}

Initially, the search process in the PubMed scientific research database allowed the identification of 2,230 articles related to the resilience scale. In the VHL database, 297 documents were found in MedLine, 11 in LiLacs and seven in IBECS. Due to the scarcity of studies conducted exclusively with individuals over 65 years of age, it was decided to select studies performed with all age groups, provided that the studies also included the elderly.

The evaluation of titles and abstracts resulted in 30 studies, of which three articles were unavailable online, meaning 27 documents were included in this study (Figure 1).

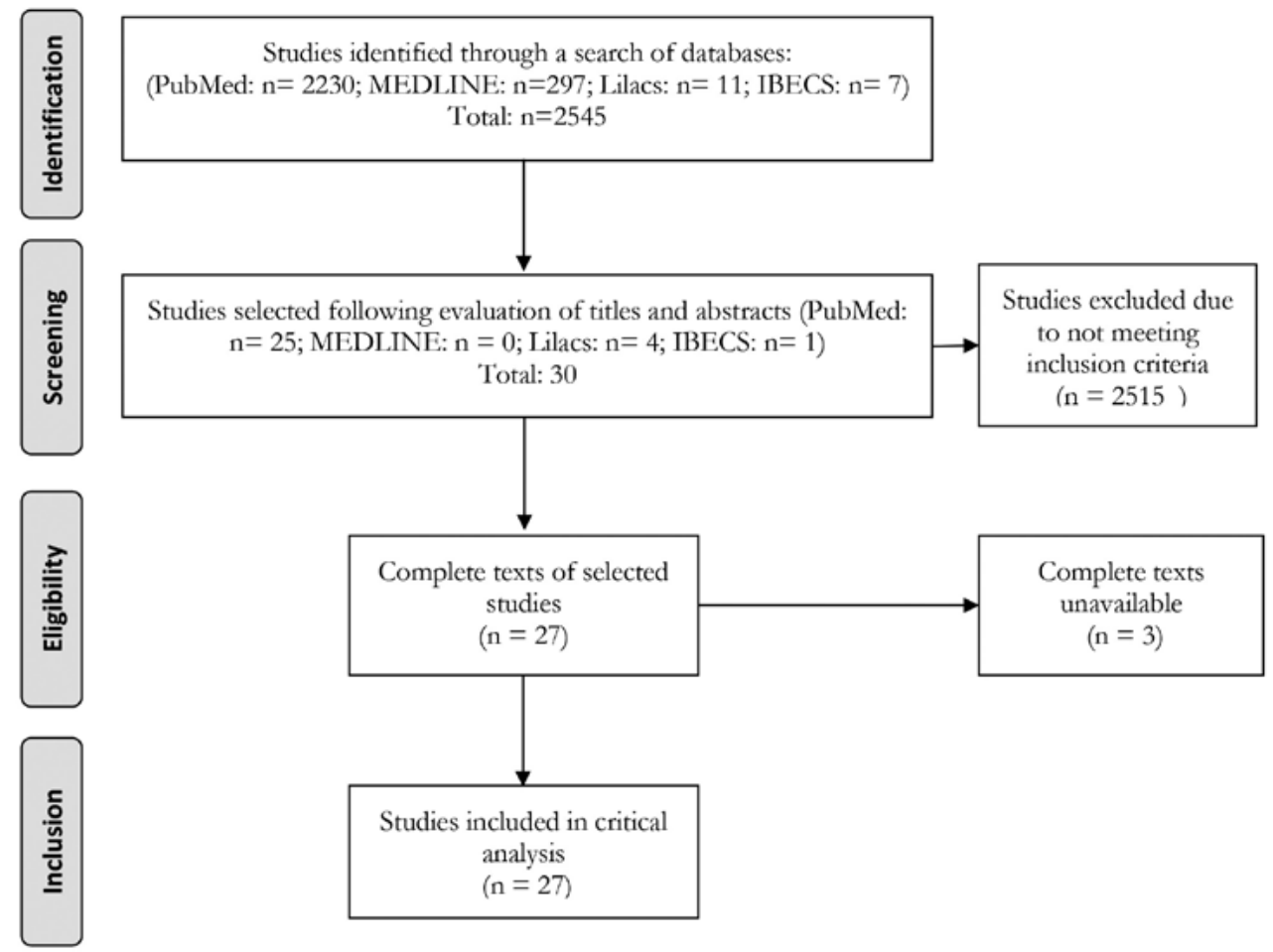

Figure 1. Schematic representation of the method of identification, screening, eligibility and inclusion of articles, adapted in accordance with the PRISMA Flow Diagram². Maringá, Paraná, 2018. 
After a critical analysis of the studies that assessed level of resilience through the Connor-Davidson scale, they were classified in relation to the authors, year of publication, journal, central theme, country, age group of participants and impact factor of the journal (Table 1).

The 27 articles selected and presented in Table 1 were conducted in 11 different countries: USA (6), China (6), Australia (5), Brazil (2), South Korea (2), Japan (1), Belgium (1), Switzerland (1), England (1), Iran (1) and Singapore (1).

The largest number of studies (11) on the level of resilience were published in 2016 . The age ranges of the studied populations included individuals from 18 to 108 years old, with five studies ${ }^{16,22,25,26,35}$ analyzing only the elderly, with ages ranging from 60 to 108 years (Table 1). No studies were identified from the databases consulted on the African continent regarding resilience levels in Elderly Persons analyzed using the Connor-Davidson scale.

All articles used in the construction of this systematic review are in journals that have been evaluated with impact factors ranging from 0.34 to 3.12 (Table 1). The quality of scientific journals is determined based on the evaluation of their respective articles, using specific criteria developed for each study design and obtained from the Equator Network website ${ }^{38}$.

Table 1 identifies the various themes related to the level of resilience. Although all research selected in this study included Elderly Persons in their samples,
CD-RISC 25 was applied in a number of situations (Figure 2) and levels of resilience in association with disease (Figure 3).

Figure 2 was elaborated based on the analysis of the 12 studies in the context of resilience in different situations, and not aimed at individuals with diseases. These studies were grouped into similar situations that resulted in five subgroups: survivors of medical procedures (2), survivors of natural disasters (1), healthcare professionals (3), elderly persons (4) and others (2). The lowest level of resilience was observed in a study conducted in Japan $(\mathrm{R}=50.8)$ with survivors of earthquakes, tsunamis and nuclear disasters ${ }^{13}$.

The five studies that were conducted exclusively with the elderly were carried out on two different continents, three in Asia ${ }^{22,24,26}$ and two in Oceania ${ }^{16,35}$. Variable resilience levels were obtained in the three studies conducted in China, with low $(\mathrm{R}=57.9)^{24}$, intermediate $(\mathrm{R}=63.6)^{26}$ and high $(\mathrm{R}=84.9)^{22}$ scores. In contrast, the two studies conducted in Australia, the first with Elderly Persons who suffered orthopedic fracture $(\mathrm{R}=73.0)^{35}$ and the second with Elderly Persons aged 100 or over $(\mathrm{R}=72.9)^{16}$, both showed medium levels of resilience.

Figure 3 shows 15 studies that assessed resilience levels in individuals with diseases: psychological trauma (2), physical problems (4), ICU patients (1), those with chronic diseases (2) and cancer (6). The highest level of resilience was observed in a study conducted in Australia with depression $(\mathrm{R}=97.3)^{34}$ and the lowest level was in Chinese women with breast cancer $(\mathrm{R}=61.0)^{25}$. 
Table 1. Characteristics of studies on resilience of the elderly according to author, year, journal, central theme, country, age group and journal impact factor, published between 2013 and 2018. Maringá, Paraná, 2018.

\begin{tabular}{|c|c|c|c|c|c|c|}
\hline Author & Year & Journal & Central Theme & Country & $\begin{array}{l}\text { Age } \\
\text { range }\end{array}$ & $\begin{array}{l}\text { Impact } \\
\text { factor }\end{array}$ \\
\hline Min et al. ${ }^{11}$ & 2013 & Supportive care in cancer & Cancer & South Korea & $18-65$ & 1.3 \\
\hline Sharpley et al. ${ }^{12}$ & 2013 & $\begin{array}{l}\text { American journal of men's } \\
\text { health }\end{array}$ & Prostate cancer & Australia & $49-84$ & 0.59 \\
\hline Kukihara et al. ${ }^{13}$ & 2014 & $\begin{array}{l}\text { Psychiatry and clinical } \\
\text { neurosciences }\end{array}$ & $\begin{array}{l}\text { Earthquake, tsunami and } \\
\text { nuclear accident survivors }\end{array}$ & Japan & $>18$ & 1.23 \\
\hline $\begin{array}{l}\text { Bahremand et } \\
\text { al. }^{14}\end{array}$ & 2014 & $\begin{array}{l}\text { Global journal of health } \\
\text { Science }\end{array}$ & Diabetes mellitus & Iran & $35-68$ & 0.42 \\
\hline Lee et al. ${ }^{15}$ & 2014 & Journal of affective disorders & Post-traumatic stress & South Korea & $20-69$ & 2.05 \\
\hline Law et al. ${ }^{16}$ & 2014 & $\begin{array}{l}\text { Archives of gerontology and } \\
\text { geriatrics }\end{array}$ & $\begin{array}{l}\text { One hundred years old } \\
\text { or older }\end{array}$ & Australian & $100-108$ & 1.01 \\
\hline Senders et al. ${ }^{17}$ & 2014 & $\begin{array}{l}\text { Journal of evidence- } \\
\text { based complementary and } \\
\text { alternative medicine }\end{array}$ & Multiple sclerosis & USA & $19-85$ & 0.48 \\
\hline Rudow et al. ${ }^{18}$ & 2014 & Progress in transplantation & Liver donors & USA & $25-72$ & 0.47 \\
\hline Ni et al. ${ }^{19}$ & 2015 & Quality of life research & General population & China & $>20$ & 1.22 \\
\hline Dubey et al. ${ }^{20}$ & 2015 & $\begin{array}{l}\text { European journal of } \\
\text { oncology nursing }\end{array}$ & Cancer & Switzerland & $29-87$ & 0.94 \\
\hline Rushton et al. ${ }^{21}$ & 2015 & $\begin{array}{l}\text { American journal of critical } \\
\text { care }\end{array}$ & ICU nurses & USA & $22-67$ & 0.78 \\
\hline Lim et al. ${ }^{22}$ & 2015 & Aging and mental health & Elderly Persons & China & $>60$ & 1.19 \\
\hline Markovitz et al. ${ }^{23}$ & 2015 & Psycho-oncology & Breast cancer & Belgium & $20-80$ & 1.67 \\
\hline Lu Canjie et al. ${ }^{24}$ & 2016 & $\begin{array}{l}\text { Archives of Gerontology and } \\
\text { Geriatrics }\end{array}$ & Elderly Persons & China & $>60$ & 1.01 \\
\hline Wu et al. ${ }^{25}$ & 2016 & Plos one & Breast cancer & China & $26-67$ & 1.16 \\
\hline Zhong et al. ${ }^{26}$ & 2016 & BMC palliative care & Elderly Persons & China & $60-91$ & 1.11 \\
\hline Zhang et al. ${ }^{27}$ & 2016 & Plos one & $\begin{array}{l}\text { Parents that had lost an } \\
\text { only child }\end{array}$ & China & $>49$ & 1.16 \\
\hline Edwards et al. ${ }^{28}$ & 2016 & $\begin{array}{l}\text { Archives of physical } \\
\text { medicine and rehabilitation }\end{array}$ & $\begin{array}{l}\text { Multiple Scleroses, } \\
\text { muscular dystrophy, }\end{array}$ & USA & $45-64$ & 1.5 \\
\hline Böell et al. ${ }^{29}$ & 2016 & $\begin{array}{l}\text { Revista latino-america } \\
\text { de enfermagem (Latin } \\
\text { American Nursing Journal) }\end{array}$ & $\begin{array}{l}\text { Chronic kidney disease, } \\
\text { diabetes, hypertension }\end{array}$ & Brazil & $>18$ & 0.34 \\
\hline Solano et al. ${ }^{30}$ & 2016 & BMC palliative care & Colorectal Cancer & Brazil & $29-86$ & 1.11 \\
\hline Hanks et al. ${ }^{31}$ & 2016 & Rehabilitation psychology & Brain injury & USA & $18-68$ & 0.71 \\
\hline Sottile et al. ${ }^{32}$ & 2016 & Critical care medicine & Intensive Care patients & USA & $>18$ & 3.12 \\
\hline Edward et al. ${ }^{33}$ & 2016 & BMC palliative care & Coronary Intervention & Australia & $>18$ & 1.11 \\
\hline Sharpley et al. ${ }^{34}$ & 2016 & $\begin{array}{l}\text { International journal of } \\
\text { psychiatry in clinical practice }\end{array}$ & Depression & Australia & $18-101$ & 1.33 \\
\hline Kohler e Loh ${ }^{35}$ & 2017 & $\begin{array}{l}\text { Australasian journal on } \\
\text { ageing }\end{array}$ & Orthopedic Fracture & Australia & $>70$ & 0.5 \\
\hline Ong et al. ${ }^{36}$ & 2018 & BMC psychiatry & $\begin{array}{l}\text { Caregivers of Elderly } \\
\text { Persons }\end{array}$ & Singapore & $21-65$ & 1.35 \\
\hline $\begin{array}{l}\text { Horvath and } \\
\text { Massey }^{37}\end{array}$ & 2018 & $\begin{array}{l}\text { Journal of forensic and legal } \\
\text { medicine }\end{array}$ & $\begin{array}{l}\text { Members of forensic } \\
\text { medicine }\end{array}$ & England & $29-73$ & 0.62 \\
\hline
\end{tabular}




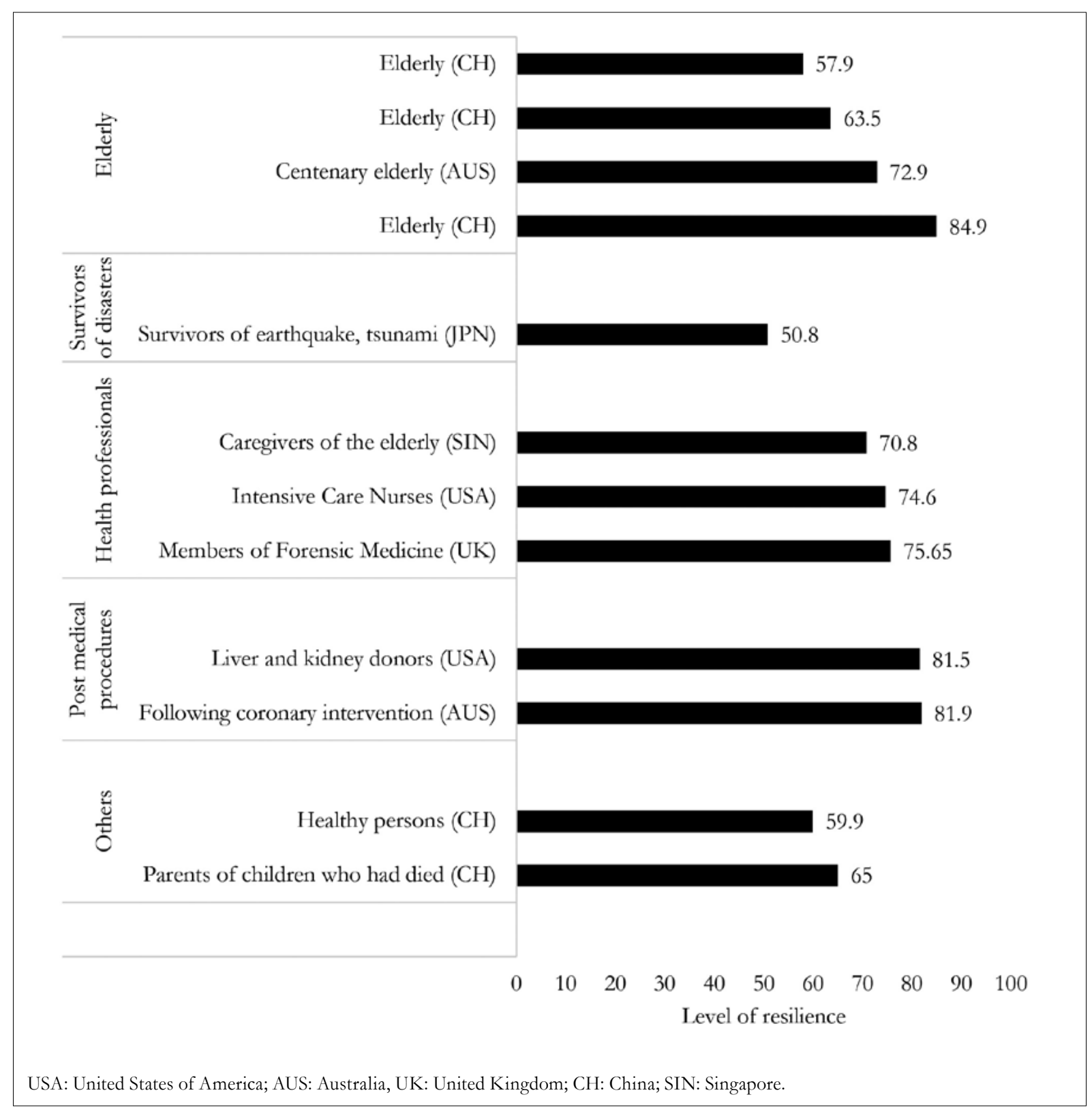

Figure 2. Classification of studies in terms of levels of resistance measured by CD-RISC 25 grouped by a range of situations. Maringá, Paraná, Brazil, 2018. 


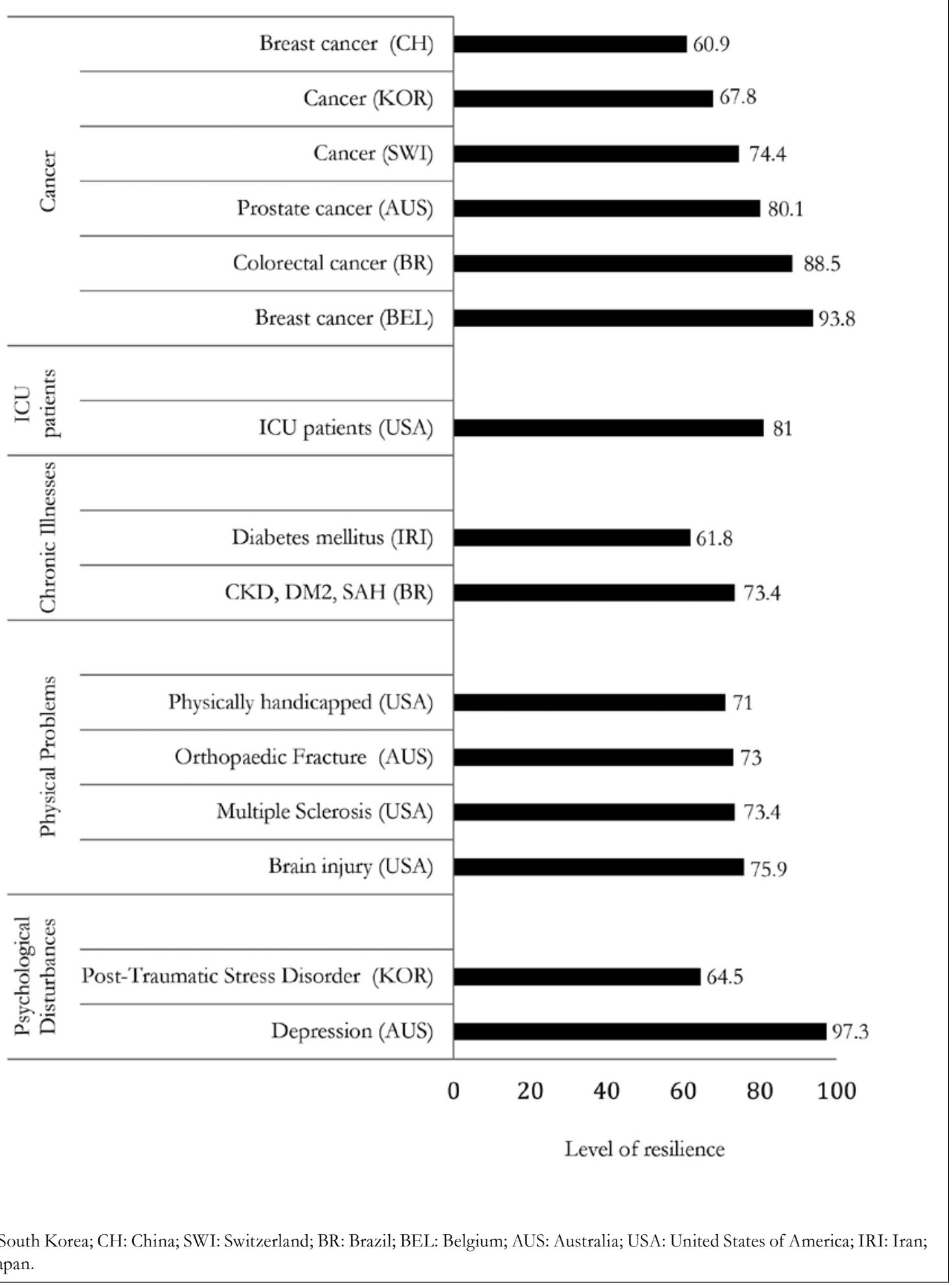

Figure 3. Classification of studies on resilience levels measured by CD-RISC 25 and grouped by disease type. Maringá, Paraná, Brazil, 2018. 


\section{DISCUSSION}

The greatest number of studies involving the measurement of resilience by the Connor-Davidson scale that included the elderly originated in the USA and China. The USA officially recognizes resilience in the doctrine of its national security strategy, which justifies the need to increase this quality among its population, including the ability to quickly resist and recover from deliberate attacks, accidents, natural disasters, as well as unconventional stresses, attacks and threats to the economy and the democratic system $^{39}$. The Department of Homeland Security also recognized resilience in its quadrennial review of national security in 2014, with the elaboration of the Quadrennial Homeland Security Review (QHSR) mission number $\mathrm{V}$ of which addresses the national preparedness for resilience ${ }^{40}$.

China, in turn, includes resilience in two philosophies: Taoism and Confucianism, cultures experienced by the most elderly persons to a significant degree. Not surprisingly, perspectives on resilience are reflected in different cultural views in China. For example, in Taoism, adversity is often interpreted by a positive, dialectical, dualistic approach. However, adversity is not necessarily understood as negative, but interpreted as an opportunity for positive change ${ }^{41}$. Self-control and moderate opinions are considered the meaning of social harmony. In addition, Taoism emphasizes the rules of dualism, revealing the cyclical oscillation between extremes, adversity, and success ${ }^{41}$.

In China, three surveys have measured the level of resilience in the population of the communitydwelling elderly population ${ }^{22,24,26}$. In the context of mental health, the results of these surveys showed that the level of resilience of the elderly is influenced by stressful life events ${ }^{22}$ and parenting style ${ }^{26}$, that is, the way parents relate to their children and family relationships in quality of life $^{24}$.

The country with the third highest number of studies, Australia is notable for the positive influence of its public policies, encouraging high levels of resilience among its population ${ }^{42}$. The Health and Medical Research Institute ${ }^{41}$ has developed the Wellness and Resilience Center, which has implemented mental health and wellness programs in South Australia through public health initiatives. The Center for Wellness and Resilience is part of the South Australian Health and Medical Institute (SAHMRI) and works with researchers, psychiatrists and neuroscientists focused on the "Mind and Brain" theme, and contributes to different spectra in health research from depression, suicide and anxiety, even resilience and well-being. With this focus on building mental health assets and growing human resilience, as well as research and treatment of mental illness, the Australian initiative is a reference and a global highlight ${ }^{42,43}$.

Regarding the high level of resilience identified in the elderly in Australia ${ }^{16,34}$, it is important to consider that the pension system in this country is recognized as one of the most sustainable on the planet, a determining factor for maintaining the quality of life of its elderly population ${ }^{44}$. Adequacy of pensions results in the ability to avoid poverty and social exclusion at an advanced age, ensuring a decent standard of living for retirees, enabling them to enjoy the economic well-being of their country and to participate in public, social and cultural life ${ }^{44}$.

Health professionals had intermediate levels of resilience ${ }^{21,37}$. These professionals are routinely faced with numerous situations that challenge their professional practices, such as: complications on duty; the countless hours worked; the challenges of dealing with death; health system problems and the frequent requirement to work double shifts. This context requires emotional stability and resilient personality development to cope with adverse situations in their daily work ${ }^{21}$. Given this situation, health professionals should develop skills to deal with their professional practice, seeking self-confidence; self-control; empathy; a perception of self-healing; optimism and meaning in life; take on challenges; be flexible; tolerant; work in teams; and deal with the losses and frustrations experienced by their patients. In this scenario and with these needs, resilience is a necessary resource to face adversity, enabling the well-being, quality of life and health of these professionals ${ }^{15}$. 
The study of resilience through adverse situations that may mean outcomes aimed at improving people's lives, such as choosing to be a living organ donor ${ }^{18}$ (liver and kidney donors), or surviving percutaneous coronary interventions ${ }^{33}$, indicated the high levels of resilience of those involved in economically stable countries ${ }^{18,33}$, unlike in China, which has an emerging economy and where the one-child policy was implemented in the early 1980s, leading to major changes in the structure of the Chinese population and its families. The study of a special group of parents whose only child ${ }^{27}$ had died indicated low levels of resilience. Parents who have lost their only child experience a variety of emotional responses such as anxiety, depression, suicide risk, and prolonged pain, living on the borderline of severe mental disorders ${ }^{27}$.

A study conducted in Japan ${ }^{13}$ found the lowest level of resilience as measured by the ConnorDavidson scale. This country is located at the edge of the Eastern Eurasian tectonic plate, and is affected by one in five of the Richter-magnitude earthquakes occurring in the world. Its population, especially the elderly, has experienced repeated situations related to these natural disasters such as tsunamis, earthquakes and, more recently, nuclear accidents ${ }^{45}$. These events when they occur in significant numbers expose the population to extreme situations to which they are vulnerable, resulting in injury and loss of life, combined with damage to property and livelihoods. Discussing recovery and resilience in natural disaster situations implies community resilience ${ }^{13}$. Mutual support is needed to enable families to share their needs and build strategies together to seek resources to continue their life projects ${ }^{46}$. In this context, Kukihara et al. ${ }^{13}$ found that some major disaster survivors were able to cope with traumatic events relatively well, and resilience was a significant protective factor in experiencing such events. It follows that it is crucial to help survivors improve their resilience by offering job opportunities and encouraging a healthy lifestyle.

The analysis of the studies selected in this review, focusing on identifying the level of resilience of the elderly in the presence of disease, found a strong consensus that resilience is an important protective factor for emotional distress, whether in the presence of diseases with greater repercussions, such as cancer ${ }^{23,25}$, or chronic diseases such as high blood pressure and diabetes ${ }^{14,29}$.

While Markovitz et al. ${ }^{23}$ identified that Belgian patients $(R=93.8)$ with greater resilience were more able to cope with the negative impact of breast cancer and were less likely to have depressive symptoms, in China Wu et al. ${ }^{25}$ found low levels $(\mathrm{R}=60.9)$ of resilience in patients with the same cancer, especially in older women. Other studies carried out in different countries with breast cancer patients showed different levels of resilience: South Korea $(\mathrm{R}=67.8)^{11}$, Switzerland $(\mathrm{R}=74.4)^{20}$, Australia $(\mathrm{R}=80.1)^{12}$ and Brazil $(\mathrm{R}=88.5)^{30}$. The variation of these results reinforces the thesis of the strong relationship of resilience with the cultural bases of different peoples, and less relation to the economic conditions of the country, since, for example, Brazilians have shown higher levels of resilience ${ }^{30}$ than those living in countries. with greater economic stability ${ }^{20}$ and better health care ${ }^{12}$.

The resilience level of individuals with diabetes mellitus in Brazil was higher than the study conducted in Iran ${ }^{14}$. In Brazil, Federal Law No. $11,347 / 2006^{47}$ provides free distribution of medicines and materials necessary for their application and the monitoring of blood glucose to patients with diabetes. For free medical consultations, receipt of medications and assistance from a multiprofessional team, the patient only needs to enroll in the special education program for diabetics (or HIPERDIA) at the nearest health center.

On the other hand, in Iran, although access to diabetes medications is affordable and covered by health plans ${ }^{48}$, a study by Bahremand et al. ${ }^{14}$ found that in that family relationships and mental health are significant interfering factors to levels of resilience, and concluded that diabetic patients who enjoyed a better family relationship had greater resilience and, consequently, better mental health.

Studies conducted in Australia ${ }^{35}$ and the USA ${ }^{17,28,31}$ have identified medium levels of resilience among people with physical disabilities due to orthopedic fractures $(\mathrm{R}=73.0)^{35}$, multiple sclerosis $\left[(\mathrm{R}=71.0)^{18}\right.$; 
$\left(\mathrm{R}=73.4^{17}\right)$ ] and brain injury $(\mathrm{R}=75.9)^{31}$. Kohler and Loh $^{35}$ discuss the importance of using physical rehabilitation environments as places to implement beneficial strategies to improve the resilience of rehabilitation patients and the elderly in coping with their physical limitations.

Although most studies selected for resilience address, in different manners, psychological issues; two studies were identified that related mental disorders to resilience. The first was conducted in China by Lee et $\mathrm{al}^{15}$, who analyzed the stress experienced by 552 firefighters with high stress levels in their daily routines, and concluded that interventions that improve resilience reduce the impact of traumatic events and, consequently, reduce the development of posttraumatic stress disorder, including in those aged 60 and older. The second study, meanwhile, developed in Australia by Sharpley et $\mathrm{al}^{34}$, identified interventional strategies and goals that were successfully implemented for the individualized treatment of patients, considering subtypes of mental disorders.

Given the above, this literature review identified that the Connor-Davidson scale is a valuable tool for use in various situations of psychological stress that can greatly affect people's quality of life. Although the initial purpose of this study was limited to assessing resilience in the elderly, the scarcity of studies targeting this population led the researchers to broaden the search for studies developed by including elderly persons together with other age groups.

\section{CONCLUSION}

The present systematic review of the scientific literature on levels of resilience measured by the Connor-Davidson instrument, which included the elderly in their samples, identified studies in 11 countries with central themes in a range of situations. The countries with the most resilience studies were China, the United States, and Australia. Analysis of the level of resilience among patients with diseases identified a study in Australia as having the highest level of resilience in elderly patients with depression. In contrast, the lowest level of resilience was found among the survivors of natural disasters in Japan, although for the older population who experienced repeated events during their lives, resilience represented a significant protective factor for survivors against such events. Almost all studies recognized the need to implement interventions to improve resilience in the face of adversity.

Future research is needed to better understand the interventions that increase the resilience of those involved, whether in adverse situations imposed by the environment in which they live, or those arising from the natural events of the aging process, in the context of health or the presence of diseases.

\section{REFERENCES}

1. United Nations Organization. Cúpula da ONU discute envelhecimento populacional e desenvolvimento sustentável [Internet]; [sem local]: ONU; 2017 [acesso em 27 out. 2017]. Disponível em: https://nacoesunidas. org/cupula-da-onu-discute-envelhecimentopopulacional-e-desenvolvimento-sustentavel/

2. Organização Mundial da Saúde. Relatório Mundial de envelhecimento e Saúde [Internet]. Genebra: Organização Mundial da Saúde; 2015 [acesso em 27 out. 2017]. Disponível em: https://sbgg. org.br/wp-content/uploads/2015/10/OMSENVELHECIMENTO-2015-port.pdf

3. Betancourt TS, Meyers-Ohki SE, Charrow A, Hansen N. Annual research review: mental health and resilience in HIV/AIDS-affected children a review of the literature and recommendations for future research. J Child Psychol Psychiatr. 2013;54(4):423-44.

4. Gayton WF, Friedman SB, Tavormina JF, Tucker F. Children with cystic fibrosis: I. Psychological test findings of patients, siblings, and parents. Pediatrics. 1977;59(6):888-94

5. Melillo A, Suárez-Ojeda EN, Rodríguez D.

Resiliencia y subjetividad: los ciclos de la vida. Buenos Aires: Paidos; 2004 
6. Souza MTS, Cerveny CMO. Resiliência psicológica: revisão da literatura e análise da produção científica. Rev Interam Psicol. 2006;40(1):115-22.

7. Smith J, Borchelt M, Maier H, Jopp D. Health and well-being in the young and oldest old. J Soc Issues. 2002;58(4):715-32.

8. Centro Internacional de Longevidade Brasil. Envelhecimento ativo: um marco político em resposta à revolução da longevidade. Rio de Janeiro: ILC; 2015.

9. Galvão TF, Pansani TSA, Harrad D. Principais itens para relatar Revisões sistemáticas e Meta-análises: a recomendação PRISMA. Epidemiol Serv Saúde. 2015;24(2):335-42.

10. Connor K M, Davidson JRT. Development of a new resilience scale: The Connor-Davidson Resilience Scale (CD-RISC). Depress Anxiety. 2003;18(2):76-82.

11. Min JA, Yoon S, Lee CU, Chae JH, Lee C, Song KY, Kim TS. Psychological resilience contributes to low emotional distress in cancer patients. Support Care Cancer. 2013;21(9):2469-76.

12. Sharpley C, Christie D, Bitsika V. Variability over time-since- diagnosis in the protective effect of psychological resilience against depression in Australian prostate cancer patients: implications for patient treatment models. Am J Men's Health.2013;7(5):414-22.

13. Kukihara H, Yamawaki N, Uchiyama K, Arai S, Horikawa E. Trauma, depression, and resilience of earthquake/tsunami/nuclear disaster survivors of Hirono, Fukushima, Japan. Psychiatr Clin Neurosci. 2014;68(7):524-33.

14. Bahremand M, Rai A, Alikhani M, Mohammadi S, Shahebrahimi K, Janjani P. Relationship between family functioning and mental health considering the mediating role of resiliency in type 2 diabetes mellitus patients. Global J Health Sci. 2014;7(3):254-9.

15. Lee JS, Ahn YS, Jeong KS, Chae JH, Choi KS. Resilience buffers the impact of traumatic events on the development of PTSD symptoms in firefighters. J Affect Disord. 2014;162:128-33.

16. Law J, Richmond RL, Kay-Lambkin F. The contribution of personality to longevity: findings from the Australian Centenarian Study. Arch Gerontol Geriatr. 2014;59(3):528-35.

17. Senders A, Bourdette D, Hanes D, Yadav V, Shinto L. Perceived stress in multiple sclerosis: the potential role of mindfulness in health and well-being. J Evid -Based Complement Altern Med. 2014;19(2):104-11.

18. Rudow DL, Iacoviello BM, Charney D. Resilience and personality traits among living liver and kidney donors. Prog Transplant. 2014;24(1):82-90.
19. Ni MY, Li TK, Yu NX, Pang H, Chan BH, Leung GM, et al. Normative data and psychometric properties of the Connor-Davidson Resilience Scale (CD-RISC) and the abbreviated version (CD-RISC2) among the general population in Hong Kong. Qual Life Res. 2016;25(1):111-6.

20. Dubey C, De Maria J, Hoeppli C, Betticher DC, Eicher M. Resilience and unmet supportive care needs in patients with cancer during early treatment: a descriptive study. Eur J Oncol Nurs. 2015;19(5):582-8.

21. Rushton CH, Batcheller J, Schroeder K, Donohue P. Burnout and resilience among nurses practicing in high-intensity settings. Am J Crit Care. 2015;24(5):412-20.

22. Lim ML, Lim D, Gwee X, Nyunt MS, Kumar R, Ng TP. Resilience, stressful life events, and depressive symptomatology among older Chinese adults. Aging Ment Health. 2015;19(11):1005-14.

23. Markovitz SE, Schrooten W, Arntz A, Peters ML. Resilience as a predictor for emotional response to the diagnosis and surgery in breast cancer patients. Psychooncology. 2015;24(12):1639-45.

24. Lu C, Yuan L, Lin W, Zhou Y, Pan S. Depression and resilience mediates the effect of family function on quality of life of the elderly. Arch Gerontol Geriatr. 2017;71:34-42.

25. Wu Z, LiuY, Li X, Li X. Resilience and associated factors among mainland chinese women newly diagnosed with breast cancer. PLoS ONE. 2016;11(12):e0167976 [13 p.].

26. Zhong X, Wu D, Nie X, Xia J, Li M, Lei F, et al. Parenting style, resilience, and mental health of community-dwelling elderly adults in China. BMC Geriatrics. 2016;16:1-8.

27. Zhang W, Wang A, Yao S, Luo Y, Li Z, Huang $F$, et al. Latent profiles of posttraumatic growth and their relation to differences in resilience among only-child-lost people in China. PLoS ONE. 2016;11(12):e0167398 [13 p.].

28. Edwards KA, Alschuler KA, Ehde DM, Battalio SL, Jensen MP. Changes in resilience predict function in adults with physical disabilities: a longitudinal study. Arch Phys Med Rehabil. 2017;98(2):329-36.

29. Böell JE, Silva DM, Hegadoren KM. Sociodemographic factors and health conditions associated with the resilience of people with chronic diseases: a cross sectional study. Rev Latinoam Enferm. 2016;24:e2786 [9 p.].

30. Solano JP, da Silva AG, Soares IA, Ashmawi HA, Vieira JE. Resilience and hope during advanced disease: a pilot study with metastatic colorectal cancer patients. BMC Palliat Care. 2016;15:1-8. 
31. Hanks RA, Rapport LJ, Waldron Perrine B, Millis SR. Correlates of resilience in the first 5 years after traumatic brain injury. Rehabil Psychol. 2016;61(3):269-76.

32. Sottile PD, Lynch Y, Mealer M, Moss M. Association Between Resilience and Family Member Psychologic Symptoms in Critical Illness. Crit Care Med. 2016;44(8):721-7.

33. Edward KL, Stephenson J, Giandinoto JA, Wilson A, Whitbourn R, Gutman J, et al. An Australian longitudinal pilot study examining health determinants of cardiac outcomes 12 months post percutaneous coronary intervention. BMC Cardiovascr Dis. 2016;16:1-8.

34. Sharpley C, Bitsika V, Jesulola E, Fitzpatrick K, Agnew LL. The association between aspects of psychological resilience and subtypes of depression: implications for focussed clinical treatment models. Int J Psychiatr Clin Pract. 2016;20(3):151-6.

35. Kohler S, Loh SM. Patient resilience in the fracture orthopaedic rehabilitation geriatric environment. Australas J Ageing. 2017;36(1):65-8.

36. Ong HL, Vaingankar JA, Sambasivam R, Fauziana $\mathrm{R}$, Tan ME, Chong SA, et al. Resilience and burden in caregivers of older adults: moderating and mediating effects of perceived social support. BMC Psychiatry. 2018;18(1):1-9.

37. Horvath MAH, Massey K. The impact of witnessing other people's trauma: The resilience and coping strategies of members of the Faculty of Forensic and Legal Medicine. J Forensic Leg Med. 2018;55:99-104.

38. The EQUATOR Network. Enhancing the Quality and Transparency of Health Research. Oxford: Minervation Ltd; 2018 [acesso em 25 de outubro de 2018]. Disponível em: http://www.equator-network.org/

39. Keeman JM. Types and forms of resilience in local planning in the U.S.: Who does what? Environ Sci Policy. 2018;88:116-23.
40. The United States. Department of Homeland Security. The 2014 Quadrennial Homeland Security Review [Internet]. [place unknown: publisher unknown]; 2014 [acesso em 27 de out. 2018]. Disponível em: https://www.dhs.gov/sites/default/ files/publications/2014-qhsr-final-508.pdf

41. Yan HQ, Tseng W, Chang S, Nishizono M. Confucian thought: implications for psychotherapy. In: Asian culture and psychotherapy: Implications for east and west. Honolulu: University of Hawaii Press; 2005. p. 129-41.

42. Hatvani-Kovacs G, Bush J, Sharifi E, Boland J. Policy recommendations to increase urban heat stress resilience. Urban Climate. 2018;25:51-63.

43. South Australian Health and Medical Institute. The Well Being and Resilience Centre [Internet]. Adelaide: SHAMRI; 2018 [acesso em 20 out. 2018]. Disponível em: https://www.wellbeingandresilience.com

44. União Europeia. Regimes privados de pensões: o seu papel nas pensões adequadas e sustentáveis [Internet]. [place unknown: publisher unknown]; 2010 [acesso em 20 de out. 2018]. Disponível em: http://ec.europa.eu/social/ BlobServlet?docId $=4853$ \&langId $=\mathrm{pt}$

45. Souza MTS. Resiliência e desastres naturais. Ciênc Cult [Internet]. 2011 [acesso em 03 abr. 2019];63(3):12. Disponível em: http://cienciaecultura.bvs. br/scielo.php?script=sci_arttext\&pid=S000967252011000300002\&lng=en

46. Landau J, Saul J. Facilitando a resiliência da família e da comunidade em resposta a grandes desastres. Pensando Fam. 2002;4(4):56-78.

47. Brasil. Lei no 11.347 , de 27 de setembro de 2006. Dispõe sobre a distribuição gratuita de medicamentos e materiais necessários à sua aplicação e à monitoração da glicemia capilar aos portadores de diabetes inscritos em programas de educação para diabéticos. Diário Oficial da União. 28 set. 2006. p. 1.

48. Ghadiri-Anari Z, Fazaelipoor SM, Mohammad. Insulin refusal in Iranian patients with poorly controlled type 2 diabetes mellitus. Acta Med Iran. 2013;51:567-71. 